Undas Vol 12. , Nomor 2, Desember 2016 : 117--133

\title{
NASKAH MANTRA MISTIK: KODIKOLOGI, SUNTINGAN DAN ISI TEKS
}

\author{
Mantra Mistik Manuscript: Codicology, Editing, and Content
}

\author{
Dede Hidayatullah
}

Peneliti Muda

Balai Bahasa Kalimantan Selatan

Jalan Jenderal Ahmad Yani Km 32,2, Loktabat, Banjarbaru 70712 Kalimantan Selatan

Telepon (0511) 4772641, Posel: dayatdh@gmail.com

\begin{abstract}
Abstrak: Selama ini, penelitian untuk naskah pengobatan belum pernah dilakukan di Kalimantan Selatan. Hal ini terjadi, karena fokus penelitian selama ini tepusat naskah keagamaan dan juga naskah sastra. Tujuan penelitian ini adalah menguraikan kodikologi dan isi yang terdapat dalam naskah pengobatan MM dengan kode E. 4508. Penelitian tentang naskah MMini adalah penelitian filologis. Metode yang digunakan adalah metode deskriptif. Secara kodikologi dapat diketahui bahwa Naskah ini ditulis menggunakan bahasa Banjar berbentuk prosa beraksara Arab Melayu yang ditulis oleh tiga orang. Naskah ini memuat tentang pengobatan, mantra kesaktian dan doa.
\end{abstract}

Kata kunci: Naskah, kodikologi, dan filologi

Abstract: During this time, in South Kalimantan, research on old traditional healing and medicine manuscript is rare. It is happened since the research mostly focuses on religious and literary manuscripts. This study aims to describe codicology and content reflected in MM healing and medicine manuscript with code E. 4508. This MM manuscript research is a philological research. The method of the research is descriptive. Codicologically, it could be found that this manuscript is written by three men in Banjar languange with Arabic Malay letters. This manuscript consists of medicine, mystical spell, and prayer supplication.

Key words: Manuscript, Codicology, and philology

\section{PENDAHULUAN}

Selama ini, kajian terhadap naskah di Kalimantan Selatan terpusat pada naskah keagamaan dan naskah syair. Untuk naskah agama, kajian naskah ini terpusat pada naskah-naskah tulisan Syekh Muhammad Arsyad al-Banjari. Memang tak bisa dipungkiri al-Banjari sangat berperan dalam penyebaran Agama Islam dan juga dalam kehidupan sosial keberagamaan masyarakat Banjar di Kalimatan Selatan melalui karya- karyanya. Peran Al-Banjari ini tidak berhenti pada masa hidupnya saja, tetapi tetap berperan dalam kehidupan keberagaman masyarakat Banjar sampai sekarang ini. Hal ini terjadi karena karya-karya al Banjari seperti Sabil alMuhtadin, masih dipelajari dan diamalkan oleh masyarakat Banjar sampai sekarang. Selain itu, naskahnaskah tulisan al-Banjari ini masih terdokumentasi dan tersimpaan dengan baik. Naskah-naskah al-Banjari ini bisa 
dilihat di Dalam Pagar dan juga di Museum Lambung Mangkurat. (Hidayatullah, 2015: 89)Selain naskah alBanjari, kajian juga dilakukan terhadap naskah keagamaan lain, seperti pada naskah Negara. Naskah ini merupakan kitab yang berisi tentang tasawuf dan tauhid yang merupakan hasil karangan beberapa pengarang. Mayoritas pengarang dalam naskah ini berasal dari Aceh seperti Risalah Syarâb al-'Âsyiqîn, karangan Hamzah Fansuri, IniFasal pada menyatakan jalan yang benar, karangan Nûr al-Dîn ibn 'Alî ibn Hasanjî ibn Muhammad Hamîd al-Rânîrî al-Syâfi'î, (Nuruddin Arraniri), Risalah IniFasal pada Menyatakan Ilmu Ma'rifatullah, dan risalah IniFasal pada menyatakan Haqiqat Niat \{risalah ini untuk menjelaskan hakikat sembahyang (mukhtașar fî haqîgat al-șalât)\} yang diberi nama Asrâr al-Salât karangan Nuruddin Arraniri. Risalah IniFasal pada menyatakan Bacaan sembahyang yang merupakan cuplikan Uș̂ul al-I'tiqâd karangan Ihsân al-Dîn ibn Muhammad Syamataranî selanjutnya akan disebut dengan Ihsanuddin Sumatrani (Hidayatullah: 2014: 1).

Penelitian-penelitian terhadap naskah Negara ini pernah dilakukan oleh beberapa orang, diantaranya; Munadi dkk (2010) meneliti salah satu bagian dari naskah negara, yaitu Ini pasal pada menyatakan Sembahyang yang membahas tentang konsep shalat menurut Ihsanuddin Sumatrani; Humaydi dkk. (2011) yang meneliti tentang isi naskah Syarâb al-'Âsyiqîn karya Hamzah Fansuri dalam Naskah Negara; dan Hidayatullah (2014) yang meneliti masalah kodikologi, suntingan teks dan isi naskah IniFasal Pada Menyatakan menyatakan jalan yang benar karya Nuruddin al-Raniri.

Adapun tentang naskah syair, kajian yang sudah dilakukan sudah banyak ditemukan. Biasanya kajian yang dilakukan berkaitan dengan tema, penokohan, dan amanat yang terdapat dalam syair itu. Naskah syair ini dapat dilihat di Museum Lambung Mangkurat, Banjarbaru, Kalimantan Selatan.

Penelitian-penelitian dan kajiankajian tentang naskah pengobatan belum pernah dilakukan. Hal ini terjadi, karena fokus penelitian selama ini hanya tepusat pada dua tersebut di atas, yaitu naskah keagamaan dan juga naskah sastra. Adapun kajian untuk naskah pengobatan seakan-akan terabaikan. Oleh karena itu, kajian ini akan membahas tentang naskah pengobatan. Objek penelitian ini adalah Mantra Mistik. Naskah Mantra Mistik ini merupakan naskah yang dimiliki oleh Museum Lambung Mangkurat Jalan Jendral A. Yani Km. 36, Banjarbaru Kalimantan Selatan. Naskah ini diberi kode Berkode E. 4508.

Selama ini, objek penelitian tentang pengobatan, terutama berkaitan dengan mantra adalah mantra yang berada di masyarakat yang di tuturkan secara turun temurun secara lisan atau masih berupa tradisi lisan. Misalnya penelitian tentang mantra Banjar yang dilakukan oleh Sunarti, dkk. (1978) dan Tim Peneliti dari Balai Bahasa Provinsi Kalimantan Selatan (2005), Rohim (2012) yang mendeskripsikan tentang mantra Banjar berdasarkan fungsinya dan nilai budaya. Dede Hidayatullah (2009 dan 2014) mendeskripsikan jenis mantra Banjar berdasarkan penggunaannya dan 
revitalisasi mantra Banjar. Adapun penelitian tentang pengobatan dalam bentuk naskah lama belum pernah dilakukan.

Dipilihnya Naskah MM sebagai objek dalam penelitian ini, karena naskah ini merupakan naskah yang lengkap dan mudah dibaca. Secara filologis, kajian terhadap naskah ini juga belum pernah dilakukan. Naskah ini secara garis besar menguraikan tentang ilmu pengobatan dan pencegahan agar tidak terkena penyakit kurap, kesaktian, dan doa-doa agar terhindar dari penyakit.

Penelitian ini akan membahas kodikologi dan isi naskah MM dengan kode E. 4508. Selain, itu akan diuraikan deskripsi isi naskahnya.Dipilihnya naskah E. 4508. ini menjadi objek dalam penelitian ini karena penelitian tentang naskah E. 4508. ini belum pernah dilakukan. Selain itu, kajian tentang pengobatan ini penting untuk dilakukan.Tujuan penelitian ini adalah menguraikan kodikologi dan isi yang terdapat dalam naskah E. 4508. Selain itu, diharapkan adanya penelitian lanjutan yang lebih mendalam tentang isi dari naskah E. 4508.

\section{KERANGKA TEORI}

Filologi menurut Baried, dkk (1994: 1-6) adalah ilmu yang berkaitan dengan naskah dan pernaskahan; sedangkan kodikologi ialah ilmu tentang kodeks (naskah) yang mengkaji sejarah naskah, kertas, tulisan, iluminasi, perdagangan naskah, dan lain-lain. Dalam perkembangannya, filologi dapat diartikan sebagai ilmu bahasa, sebagai ilmu sastra tinggi, atau ilmu teks. Sementara itu Nabilah Lubis dalam Tjandrasasmita (2006: 8) mendefinisikan filologi sebagai ilmu pengetahuan tentang sastra, yang dalam arti luas mencakup bahasa, sastra dan kebudayaan. Filologi merupakan disiplin ilmu yang berguna untuk meneliti bahasa suatu karya melalui kajian linguistik, makna kata-kata, dan penilain terhadap ungkapan bahasa sastra. Menurut Yudiafi \& $\mathrm{Mu}^{\prime}$ jizah (2010: 1.5), filologi adalah suatu disiplin ilmu tentang teks yang terekam dalam tulisan masa lampau. Studi teks ini didasari oleh adanya informasi tentang hasil budaya manusia pada masa lampau yang tersimpan di dalamnya. Oleh sebab itu, sebagai satu disiplin ilmu, filologi tergolong ke dalam ilmu humaniora yang bertujuan mengungkapkan hasil budaya masa lampau yang terekam dalam karya yang berupa tulisan (teks). Sedangkan kodikologi atau ilmu pernaskahan adalah ilmu bantu filologi yang bertugas menangani masalah fisik naskah. Kodikologi merupakan ilmu yang menguraikan dan mempelajari bahan tulisan tangan, seluk beluk semua aspek naskah, termasuk di dalamnya bahan, umur, tempat penulisan, dan perkiraan penulisan naskah. Kodikologi bertujuan untuk mendapatkan pengetahuan yang menyeluruh mengenai proses pembuatan dan pemakaian naskah, termasuk di dalamnya mengetahui orang-orang yang berkaitan dengan naskah. (Mulyadi, 1994:5 dan Mu'zijah 2005: 3).

Dalam tradisi keilmuan Arab, filologi dapat disandingkan dengan ilmu tahqiq, yaitu mentahqiq teks-teks. Mentahqiq sebuah teks berarti mengetahui secara yakin tentang 
naskah, penulisnya, mengetahui bagaimana naskah itu bisa disandarkan kepada penulisnya, melakukan kegiatan kritik teks yang nantinya bisa mengetahui tentang keaslian dari dan kedekatannya dengan naskah yang pertama dibuat. (Abdussalam Harun, 1998: 42) tahqiq juga menguraikan tentang melihat sejauh mana hakikat sesungguhnya yang terkandung di dalam sebuah teks; mengetahui suatu berita dan menjadi yakin akan kebenarannya. Oleh karena itu yang dimaksud dengan men-tahqiq adalah pengetahuan hakiki tentang suatu teks.( Diyab, 1993:133-134)

Dalam tradisi penelitian modern, filologi dipandang sebagai studi yang melakukan penelaahan dengan mengadakan kritik teks. Dalam ungkapan lain, filologi adalah studi tentang seluk beluk teks. Filologi juga digunakan sebagai perangkat pengetahuan dengan studi teks sastra atau budaya yang dikaitkan dengan latar belakang kebudayaan yang didukung oleh teks. Sementara di sisi lain, filologi dipakai sebagai alat untuk melacak isi teks lama dan transmisinya seperti yang dikhususkan pada teks-teks lama; menjadi semacam linguistik historis. (Tjandrasasmita, 2006: 16--17)

Dalam konteks ini, titik temu antara ilmu filologi dengan ilmu tahqiq terletak pada usaha untuk memeriksa dan mengoreksi sebuah tulisan. Baik tahqiq maupun filologi, keduanya merupakan usaha keras untuk menampilkan karya klasik dalam bentuk yang baru dan mudah dipahami. Oleh karena itu, studi filologi atau ilmu tahqiq dapat dipandang sebagai usaha penelaahan terhadap sebuah naskah untuk menciptakan kembali teks yang di dalamnya terdapat pengungkapan kegiatan yang kreatif untuk memahami, menafsirkan dan membetulkan teks jika ditemukan sesuatu yang dipandang tidak tepat. Proses pembetulan harus dikaitkan dengan ilmu bahasa, sastra, budaya, keagamaan dan tata politik yang ada pada zamannya (Hidayatullah, 2014: 6).

Menurut Jamaris (2009, 5-9), ada beberapa hal pokok yang harus dilakukan dalam penelitian filologi.

1. Inventarisasi naskah. Inventarisasi naskah adalah kegiatan mendaftarkan semua naskah yang terdapat di berbagai perpustakaan universitas atau museum yang biasa menyimpan naskah. Daftar naskah dapat dilihat berdasarkan katalogus naskah yang tersedia.

2. Kodikologi atau deskripsi naskah. Kodikologi atau deskripsi naskah adalah kegiatan membuat uraian yang berisi kode dan nomor naskah (kalau ada), judul, pegarang, penyalin, tahun salinan, tempat simpanan, asal naskah, pemilik naskah, jenis alat, kondisi fisik, penjilidan, water marks, garis tebal/tipis, jarak antar garis tebal, jarak antar tipis, garis dengan tinta, skrip pensil, jumlah kuras, jumlah halaman, jumlah isi, dan sejauh mana isi naskah itu.

3. Perbandingan naskah. Perbandingan naskah perlu dilakukan, apabila sebuah cerita ditulis dalam dua naskah atau lebih untuk membetulkan kata-kata yang salah atau tidak terbaca; untuk menentukan sisilah naskah; untuk mendapatkan naskah yang terbaik; 
dan untuk tujuan-tujuan lain. Perbedaan-perbedaan yang terdapat dalam naskah-naskah itu timbul, sebab naskah itu diperbanyak dengan menyalin. Dalam menyalin kembali itu terdapat banyak kesalahan dan penambahan baru, karena cara yang dilakukan dalam menyalin naskah itu bermacammacam sesuai dengan kepandaian dan keinginan si penyalin.

Dari pengamatan sementara, dapat disimpulkan di sini cara yang dilakukan dalam menyalin naskah itu sebagai berikut:

a. menyalin dengan membetulkan;

b. menyalin dengan menggunakan bahasa sendiri;

c. menyalin dengan menambah unsur atau bagian cerita baru, karena adanya pengaruh asing; dan

d. menyalin cerita dari cerita lisan atau sumber yang berbeda.

Hal-hal inilah yang menyebabkan perlunya naskah itu diperbandingkan. Sudah menjadi ciri sastra lama, bahwa pengarang atau penyalin cerita bebas menambah, mengubah atau memperbaiki ceritera yang diperolehnya. Meskipun demkian, tentu ada batas-batasnya juga, sepanjang isi atau pokok ceritanya tidak berubah, karena mengubah suatu tradisi tabu bagi masyarakat lama. Masyarakat lama menganggap naskah itu sebagai warisan atau pusaka yang tinggi nilainya. Hal inilah yang memberi jaminan pada kita, bahwa isinya dapat dipercayai, betulbetul hidup dalam masyarakat sesuai dengan kepercayaannya dan tidak dikarang sesuka penulisnya.

\section{METODE PENELITIAN}

Penelitian tentang naskah MMini bisa dikategorikan sebagai penelitian filologis. Adapun proses penelitian yang dilakukan adalah sebagai berikut.

Pertama, menentukan teks yang akan disunting. Teks yang akan disunting dalam penelitian ini adalah teks MM.

Kedua, melakukan deskripsi fisik naskah atau kodikologi danmembuat form yang memuat elemen-elemen yang akan diteliti. Elemen-elemen yang dimaksud adalah kode dan nomor naskah (kalau ada), judul, pegarang, penyalin, tahun salinan, tempat simpanan, asal naskah, pemilik naskah, jenis alat, kondisi fisik, penjilidan, water marks, garis tebal/tipis, jarak antargaris tebal, jarak antartipis, garis dengan tinta, skrip pensil, jumlah kuras, jumlah halaman, jumlah isi.

Ketiga, melakukan suntingan teks MM. Dalam hal ini peneliti menggunakan teknik Edisi standar, yaitu menerbitkan naskah dengan membetulkan kesalahan-kesalahan kecil dan ketidakajegan, sedangkan ejaannya disesuaikan dengan ketentuan yang berlaku. Diadakan pembagian kata, pembagian kalimat, digunakan huruf besar, pungtuasi, dan diberikan pula komentar mengenai kesalahankesalahan teks. Pembetulan yang tepat dilakukan atas dasar pemahaman yang sempurna sebagai hasil perbandingan dengan naskah-naskah sejenis. Semua perubahan yang diadakan dicatat di tempat yang khusus agar selalu dapat diperiksa dan diperbandingkan dengan bacaan naskah sehingga masih memungkinkan penafsiran lain oleh pembaca. Segala usaha perbaikan harus disertai pertanggungjawaban dengan 
metode rujukkan yang tepat (Baried, 1994: 69).

Keempat, melakukan analisis untuk menguraikan isi teks MM. Analisis dilakukan dengan cara menguraikan isi naskah berdasarkan pasal dan/atau bab yang ada dalam MM, kemudian dijelaskan tentang isi setiap pasal dan bab tersebut.

\section{ANALISIS DAN PEMBAHASAN}

\section{Deskripsi Naskah}

Naskah MM yang Berkode E. 4508 ini di simpan di Museum Lambung Mangkurat Jalan Jendral A. Yani Km. 36, Banjarmasin. Naskah ini bersampul kertas karton tebal berwarna coklat dan alas naskah kertas tebal. Ukuran naskah $10 \times 6,5 \mathrm{~cm}$, ukuran teks $7 \times 4 \mathrm{~cm}$, tebal naskah 61 halaman. Jumlah baris setiap halaman 7 baris. Kecuali pada halaman 57 yang hanya berisi 4 baris dan dua ilmunisasi, dan halaman 56 yang merupakan akhir dari pembahasan bab. Halaman awal dan akhir Teks MM ini kosong, sedangkan halaman 56 (58) yang ditulis dengan pensil dicoret dan diulang lagi penulisannya pada halaman 59.

Penomoran halaman terletak di atas tengah dan pojok kanan atas. Penomoran naskah ini ditulis dengan pensil menggunakan angka latin, penomorannya di mulai dengan angka 2, halaman sampul dalam tidak ditemukan ada penomoran, tetapi dapat diduga bahwa penomoran ini di mulai dari sampul dalam ini. Selain itu, penulisan nomor ini dilakukan untuk memudahkan membaca naskah ini, dan bukan dilakukan oleh penulis/penyalin naskah. Halaman di samping halaman 2 tidak ditulis halaman 3, justru halaman 3 nya ditulis di halaman 4 . Selanjutnya penomorannya menggunakan angka ganjil, 3,5,7, dan seterusnya. Pada halaman 19, penomoran ini tidak ditulis. Justru pada halaman 21, malah tertulis halaman 19. Oleh karena itu, sesudah halaman 17, antara halaman naskah dengan penomoran yang tertulis berbeda. Apabila yang tertulis halaman 19 , seharusnya halaman adalah halaman 21 secara urutan naskah.Oleh karena itu, dalam penyuntingan naskah, penulis menuliskan halaman naskah sesudah halaman 18 sebagai beriku '21 (19)'. Angka 21 itu menunjukkan halaman secara urutan naskah, sedangkan angka 19 dalam kurung merupakan angka yang tertulis di naskah.

Pada halaman judul bagian dalam ada iluminasi seperti seekor burung yang di dalamnya tertulis tîb. di bawah iluminasi itu tertulis ini yang punya tîb. iluminasi ini menunjukkan logo si pemilik naskah. di halaman 23 (21) ada gambar dua kepala dengan ukuran yang berbeda (besar dan kecil) di jidat ada tulisan Allah dan di mulut ada tulisan Muhammaduh. Gambar kepala yang ukuran besar kedua telinganya lebar panjang dan di gambar mata serta hidung juga ada tulisan Allah di dahinya dan tulisan Muhammad $\mathrm{w}$ h di mulutnya. Selain itu, iluminasi juga terdapat pada halaman 57 (55) Iluminasi ini berbentuk 2 buah bulatan. Satu bulatan berisi tulisan : Muhammadun ilahun, ilahun Allah, sedangkan bulatan yang lain berisi rajah, yang tulisannya tidak berbentuk kalimat, tetapi hanya simbol-simbol dalam huruf Arab saja. Jadi, pada halaman judul tidak tertulis judul besar. 
Penamaan Mantra Mistik sendiri merupakan penamaan yang diberikan pemilik teks.

Pada naskah ini juga terdapat tulisan yang ditulis vertikal, seperti pada halaman 5 Teks Șifatu l-Lâh ini tertulisan vertikal di samping kata 'Zâtu l-Lâh'. teks ini merupakan tambahan dari bacaan yang harus dibaca. Hal ini bisa jadi karena penyalin tertinggal saat menyalin bacaan ini. Dan juga pada halaman 55 (53) kalimat yâ hayya l-là̇î yuhyi l-mauta, tertulis vertikal yang merupakan sambungan dari teks mantra Melepaskan Penyakit Hati.

Naskah ini ditulis menggunakan bahasa Banjar berbentuk prosa beraksara Arab Melayu. Naskah ini dan Jawi berbentuk prosa. Tulisan pada naskah ini menggunakan tinta berwarna hitam dan pensil sebagai penomoran. Seperti yang disebutkan sebelumnya, penomoran ini diduga dilakukan bukan oleh penulis/penyalin naskah. Untuk membedakan antara teks yang berbahasa Banjar dan bahasa Arab. Penulis menyertakan syakal atau baris tatkala menuliskan teks yang berbahasa Arab. Sebaliknya, ketika menulis teks yang berbahasa Banjar, tidak disertai syakal atau baris. Selain itu, penulis juga menebalkan tinta ketika memulai penulisan pasal dan bab yang baru.

Teks ditulis dengan khat riq'î kecuali ketika memulai pasal dan Bab. Pada saat memulai pasal dan Bab, penulis biasanya menggunakan khat sulusis .

Watermark dalam naskah ini seperti gambar mahkota kerajaan di halaman 3, $23,25,35,39,51$, dan 57. Kondisi naskah masih baik dan masih jelas terbaca. Kalimat awal teks berbunyi 'Ini
Sumpah Kurap. Hai Raja Jin, Ikam jangan bahinggap di kulitku karena kulitku kulit wujud Allah.' dan kalimat akhir teks berbunyi 'ini rajah maka surat ngarannya'.

\section{Deskripsi Isi Teks}

Naskah ini tidak mempunyai daftar isi. Penulisan naskah pada halaman 2 dimulai dengan tulisan tentang sumpah kurap. Diduga teks yang berisi tentang sumpah kurap atau anti kurap ini disalin oleh orang yang berbeda dengan penyalin utama naskah ini. Hal ini disebabkan oleh dua hal: pertama, tulisan dalam naskah utama ini berbeda dengan tulisan pada teks Ini Sumpah Kurap; kedua, pada naskah utama setiap pergantian judul selalu di mulai dengan menggunakan kata pasal, baik dengan kata 'Ini Pasal' ataupun Cuma menggunakan kata 'Pasal'. Pada akhir naskah, yaitu pada bagian Ini kata sapu, juga ditulis oleh orang yang berbeda dengan penulis sebelumnya, hal ini bisa terlihat dari bentuk huruf dan juga kerapian tulisan. Selain itu, juga mantra ini tidak ditulis secara lengkap.

Secara tulisan dan Isi, teks MM ini bisa dibagi tiga bagian dari tiga orang penulis naskah ini. Adapun secara tulisan, naskah ini terbagi ke dalam tiga bagian. Bagian yang pertama yang merupakan tulisan tentang sumpah kurap $^{1}$ dan mantra tatkala bergaul dengan orang yang menderita campah agar tidak tertular campah.

\footnotetext{
${ }^{1}$ Kata sumpah di sini bermakna mantra/ucapan penolak bala, sumpah kurap ini bertujuan agar penyakit kurap tidak menyerang si pembaca sumpah kurap.
} 
Bagian kedua, terdiri dari pasal dan bab, serta doa yang ditulis oleh seorang penulis. Adapun pasal-pasal yang terdapat dalam bagian ini berbicara dua hal, yaitu tentang cara bersahabat dengan jin, dan kesaktian. Pasal-pasal tersebut adalah

- Pasal jika hendak bersahabat jin. Pasal ini berbicara cara bersahabat dengan Jin.

- Ini Pasal Lampah Kagancangan. Pasal ini menguraikan tentang kesaktian dan kekuatan pukulan.

- Ini Pasal pakai menundukkan musuh. Pasal ini memuat bacaan yang dibacakan ketika bertemu dengan musuh, agar musuh itu tunduk.

- Ini Pasal Kagancangan. Pasal ini memuat tentang cara mendapatkan kesaktian dan kekuatan dengan berpuasa.

- Ini Pasal Kagancangan Jin. Pasal ini memuat tentang cara mendapatkan kesaktian dan kekuatan seperti kekuatan Jin.

- Ini pasal kagancangan. Pasal ini memuat tentang cara mendapatkan kesaktian dan kekuatan dengan mandi.

- Ini Pasal lampahnya Kebal. Pasal ini memuat tentang cara mendapatkan kekebalan dengan menggunakan kekuatan cahaya matahari.

- Ini Pasal Isim Jalalah.Pasal ini memuat cara agar dikasihi orang dengan mandi.

Adapun Bab yang terdapat pada bagian ini berbicara tentang Bab Japaian, Bab Isim Puji Dina, dan Bab Kata Kunci. Bab Japaian berbicara tentang bagaimana cara memegang lidah dan puting susu sendiri dengan bacaannya. Bab Puji Dina berbicara tentang bacaan yang sangat besar manfaat dan akan mendapat pertolongan ribuan malaikat untuk pembacanya ketika melakukan sesuatu. Sedangkan Bab Kata Kunci mengungkapkan tentang cara agar seseorang terkunci atau terbungkam sehingga tidak bisa beristri atau bersuami, dan musuh tidak bisa menyerang.

Pada bagian doa, terdapat beberapa macam doa, yaitu doa Kandung Rasulullah, doa agar memperoleh kewibawaan dan pangkat, doa melepaskan segala kejahatan, doa melepaskan segala penyakit hati, dan satu azimat agar kebal. Doa kandung Rasulullah itu mempunyai banyak khasiat, diantaranya mendapat rezki yang tiada putus, disayangi sama pembesar dan atasan, disayangi kekasih, dapat mengetahui dan melihat orang yang berada dalam kubur, dapat melihat malaikat dan setan, mempunyai pengaruh dan selalu dipatuhi, ditakuti binatang, membuat air laut menjadi tawar, agar orang tidak jadi berbuat jahat, agar sawah dan ladang tidak dimakan tikus, meredakan ombak dan angin besar, agar selamat di negeri orang.

Teks Agama disalin seteliti mungkin sehingga jarang terjadi penambahan atau pengurangan mengenai gagasangagasan pokok yang disajikannya. Demikian juga dalam mentransliterasi naskah ini, harus dilakukan dengan seteliti mungkin sehingga gagasangagasan pokok yang disajikannya tidak mengalami perubahan. Dalam mentransliterasi teks tersebut, dipakai beberapa ketentuan sebagai berikut.

1. Kata-kata Arab yang sudah diserap ke dalam bahasa Indonesia, 
penulisannya disesuaikan dengan Ejaan Yang Disempurnakan. Misalnya kata gā $\grave{\imath} b$ akn ditulis dengan gaib jika berada dalam konteks bahasa Indonesia, tetapi akan ditulis $g \bar{a} \mathfrak{\imath} i b$ kalau berada dalam konteks Arab.

2. Kata atau kalimat yang menggunakan huruf miring pada transliterasi MM berasal dari teks.

3. Kata yang salah dibetulkan dan pembetulannya dimuat dalam teks, sedangkan aksara aslinya dicatat pada catatan kaki.

4. Kata yang ditulis dalam dua bentuk, dipilih satu bentuk untuk menjaga kekonsistenan. Misalnya ḍahir dalam teks ditulis dahir, dalam bahasa Indonesia ditulis dengan lahir dan dalam transliterasi kata tersebut dialihaksarakan dengan lahir.

5. Kata ulang yang ditulis dengan angka dalam transliterasi ditulis dengan kata yang diulang dan menggunakan tanda hubung (-).

6. Kata yang berada dalam tanda kurung $\{\ldots . .$.$\} berarti ada dalam teks,$ tetapi dianggap tidak ada dalam pembacaan

7. Tanda [.... tambahan dari penyunting karena kata itu kurang atau salah dalam penulisannya sehingga perlu ditambahkan.

8. Teks dalam naskah tidak memakai tanda baca. Namun, untuk keperluan pembacaan, dalam alih aksara dilakukan pembagian alenia, penggunaan huruf kapital, dan tanda baca yang pemakaiannya disesuaikan dengan Ejaan Yang Disempurnakan.
9. Kata yang tidak dapat dibaca dalam alih aksara hanya dicatat huruf demi huruf dari kata itu dan huruf aslinya (aksara Arab) dicatat pada catatan kaki.

10. Kata-kata Indonesia yang berasal dari bahasa Arab dan sudah baku, tetapi belum memasyarakat ditulis dengan huruf miring dan akan diberi arti dalam daftar kata Arab.

11. Kata yang sudah tidak lazim dipakai tetap dipertahankan sesuai dengan aslinya.

12. Ada dua pedoman yang dipakai untuk pegangan dalam alih aksara. Pertama, Pedoman Ejaan Yang Disempurnakan dan Pedoman Transliterasi Arab Latin (1987) digunakan untuk alih aksara kata dan kalimat berbahasa ArabPedoman transliterasi Arab-Latin itu dicatat di bawah ini.

13. Kata-kata Arab yang berakhiran huruf $t$ lalu bersambung dengan kata Arab berikutnya, ditambah dengan huruf tersebut. Misalnya, qiblatu $l-$ muslimin.

\begin{tabular}{|c|c|c|c|}
\hline Arab & Latin & Arab & Latin \\
\hline 1 & $a$ & b & $\underline{t}$ \\
\hline ب & $b$ & b & Z \\
\hline ت & $t$ & $\varepsilon$ & - \\
\hline$\dot{H}$ & $\dot{\mathrm{S}}$ & $\dot{\varepsilon}$ & $\mathrm{g}$ \\
\hline ج & $\mathrm{j}$ & ف & $\mathrm{f}$ \\
\hline$\tau$ & $\mathrm{h}$ & ق & $q$ \\
\hline$\dot{\tau}$ & $\mathrm{kh}$ & ك & $\mathrm{k}$ \\
\hline$د$ & $\mathrm{~d}$ & $J$ & 1 \\
\hline$j$ & $\dot{Z}$ & م & $\mathrm{M}$ \\
\hline 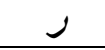 & $r$ & ن & $\mathrm{n}$ \\
\hline j & Z & و & $\mathrm{W}$ \\
\hline س & $\mathrm{S}$ & ه & $\mathrm{h}$ \\
\hline
\end{tabular}




\begin{tabular}{|c|c|c|c|}
\hline ش & sy & $\varepsilon$ & ' \\
\hline ص & $\underline{S}$ & ي & $Y$ \\
\hline ض & $\dot{\mathrm{d}}$ & & \\
\hline
\end{tabular}

\section{Suntingan Teks}

\section{Naskah Mantra Mistik²}

Ini Sumpah Kurap

Hai Raja Jin, Ikam jangan bahing/gap di kulitku karena kulitku/ kulit wujud Allah./

Ini papadahnya, kita membaca tiga kali lalu/ ditiupkan dan diludahi/ gosokakan pohon ....(naskah sobek pada kata terakhir.)

(teks ini dibuat bersambung dengan halaman berikutnya, seperti catatan kaki)

Ini diamalkan kalau kita terkumpul orang/ berkurap atau orang campa $\{\mathrm{K}\} \mathrm{h}$ kudung/ ini katanya Bismlillah wa sabakâtu l-Lâh wa kūlan alaih.//1//

\begin{tabular}{|c|c|c|c|}
\hline Hadapan & Belakang & Kanan & Kiri \\
Jibril & Israfil & Izrail & Mikail \\
Darussalam & Diyassalam & $\begin{array}{c}\text { Tabuniyah } \\
\text { Saleh }\end{array}$ & Bâardarakiyah \\
\hline
\end{tabular}

Bismillahirrahmânirrâhîm/

\footnotetext{
${ }^{2}$ Naskah ini berjudul Mantra Mistik. Pada halaman judul bagian dalam ada iluminasi seperti seekor burung yang di dalamnya tertulis tîb. di bawah iluminasi itu tertulis ini yang punya tîb. iluminasi ini menunjukkan logo si pemilik naskah.
}

Dua talu besi partiwi batu ampuampukul/ wai nal Haq, tabulik kepadanya yang manikam.

Ini kita ketahui rajanya. Ini nama raja yang laki/ 'Barjan' dan namanya yang bini 'Barjang' / / 2/ /

/ / Halaman selanjutnya kosong/ /

Pasal jika hendak bersahabat/ jin. empat akan lampahnya.Bermula pada hari Ahad/ membaca malam empat puluh/ kali dan siang empat puluh / kali berturut-turut sampai kepada/ hari kamisserta kita//4// kurangi makan kita, jangan seperti/ yang sudah-sudah. Bersih diri kita / serta memakai baubauan./ Yang dibaca amalnya di dalam hari Ahad itu inilah.. Sifatullah ${ }^{3}$ Zâtu lLâh lâilâha illa l-Lâh./

Apabila sampai malam jumat pada//5// orang tidur maka kita/ berjaga serta memasang lilin./ Jangan dibaca lagi kalimat itu, hingga yang dicita-cita di dalam/ hati mangiyau jin islam/yang empat orang yang bernama ba/gusala(m)rdan baguskidul//6// dan bagus kulon. Lamun/ inya datang bermula di/ atasnya pucuk lilin./ Jangan bermandak kita mamanda/ng lilin. Lamun inya berkata/ demikianlah bunyinya, "Apa engkau/ pinta, maka manyaru padaku//7// maka kita jawab barang apa/ maksud kita, jangan banyak per/ minta ini itu atau kata kita, "Adapun kula manyaru andika/ ini, kula handak berjanji pada/ andika berempat ini kalau ada/ barang kerja kula andika yang kula//8// harapharap inilah janji kepada kula.

\footnotetext{
${ }^{3}$ Teks Șifatu l-Lâh ini tertulisan vertikal di samping kata 'Zâtul-Lâh'. teks ini merupakan tambahan dari bacaan yang harus dibaca. Hal ini bisa jadi karena penyalin tertinggal saat menyalin bacaan ini.
} 


\section{Ini Pasal Lampah Kagancangan}

Semalaman malam empat belas, malam/ jumat, mencabut kayu sekali,/ membaca ini sekali, mencabut/ jangan barmandak semalaman tiada/ boleh talipat batis kedua.//9// Atau takubur papatungnya tiada kadapatan orang. Inilah yang dibaca/ 'Nasrum mina l-Lâhi wa fathun qarîb/ wa basysyri l-mu'minin.

Ini Pasal/ pakai menundukkan musuh. / Maka di\{ti\}upkan tiga kali pada $\mathrm{mu} /$ suhBismillahhirrahmânirrâhîm//10// lâilâha illa l-Lâhu l-wâhidu l-qahhâr,/ lâilâha illa l-Lâhu l-'azîzu l-gaffâr,/ lâilâha illa l-Lâhu wahdahu lâ syarika/ lahu ilâhan wâhidan wa nahnu lahu muslimun,/lâilâha illa l-Lâhu wahdahu lâ syarika lahu/ ilahan wâhidan wa nahnu lahu/ mukhlișun, lâilâha illa l-Lâhu//11// muhammadu rRasulullahhi bihaqqi Muhammadin wa âlihi wa șahbihî ajma'în.

Ini Pasal/ Kagancangan. kalau ada upih mengandung banyu, maka kita / baca ini lalu kita kinum ja/ngan manulih ka kiri ka kanan lalu//12// maluncat tiga kali balalu puasa sahari itu. Inilah yang dibaca, Jabtu l-japilūn jallâhu lâilâha/ illa lLâhu berkat muhammadu rRasulullâhi.

Ini Pasal Kagancangan Jin. empat puluh akan lampahnya//13// pada hari jumat bermula timbul/ matahari serta puasa kan./ papatangnya kedapatan orang, kedua/ menga\{n\}tuk, ketiga buang banyu besar, keempat berludah tempat/ kedudukan membaca itu sekali./ Membaca sekali menarik nafas//14/ / jangan berhenti, sehari itu manjapai mayat hilang. Inilah ayatnya, "Lâ tudrikuhu l-absâr wa huwa/ yudriku labsâr wa huwa/ l-latîfu l-khabîr.

\section{Ini pasal / kagancangan.}

Lampahnya tujuh//15// subuh mu\{n\}lai membaca tiga/ kali sesudah timbul, mengata/ seperti itu jua kirakira genap./ papa[n]tangnya tilasan kita mandi/ itu tida bulih dijapai/ orang dan kita tiada bulih/ setubuh dengan perempuan//16// di dalam tujuh hari inilah/ yang dibaca, "Bismillâhirrahmânirrâhîm, ahdâmun ahdun haqqun.

Ini pasal/ kagancangan, lampahnya tujuh hari,/ pagi-pagi barandam ${ }^{4} \mathrm{di}$ dalam air/ hingga pusat, maka kita tilik cahaya yanghijau di \{h\}ujung//(17)// jantung. Maka kita naikkan/ dengan nazar kita s\{y\}ir dengan/ nafas kita perlahan-lahan, maka/ naikkanlah cahaya itu daripada/ aurat tulang belakang hingga/ sampai kepada buku leher ber/ himpunlah ia di situ//18// kira-kira dua tiga nafas lamanya/ berhenti cahaya itu, maka/ lalu kita turunkan kepada seklian/ tubuh kita itu hijau semuanya,/ maka hendaklah dipandang/ yakin-yakin, jangan ada tubuh/ kita berasa, dan babuka,//19 (17) / dan ranggang, dan balobang,/ dan batulang, dan badaging, dan/ badarah, baurat, hanya/ semata cahaya yang hijau insya Allah Ta`ala.

\section{Ini Pasal lampahnya Kebal}

Memandanga matahari jadi//20 (18)// kebesaran.Lampahnya empat puluh hari mandi, bermula timbu $\{1\}$ matahari, serta kita rupa/kan di banyu serta kita masuki di dalam lobang ha ini, kemudian/ pandang matahari, kita rupakan/ di dalam matahari seperti

\footnotetext{
${ }^{4}$ berendam
} 
ini//21 (19)// jua cahayanya, seperti/ kita tarik dengan nafas,/ kita rupakan di muka kita/ seperti ini jua cahayanya/ seperti matahari atau di banyu/ atau dia matahari matahari atau dia//22 (20)// muka kita seperti ini petanya

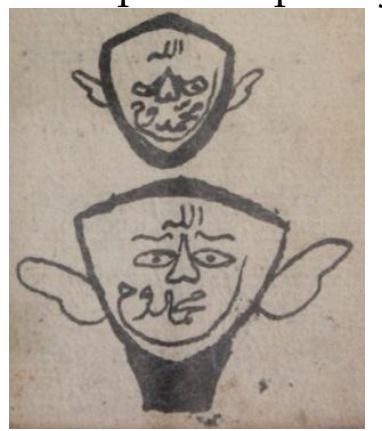

//23 (21)// Bab Ini Japaian, maka kita/ japai ujung ilatlawan/ jari manis kanan serta/ ujung ujung susu kita kanan, makrifatnya dari dapat nafas/ katanya HUWA L-LLAH. Kemudian japai/ pulang ujung ilat lawan//24 (22)// jari manis kiri,Japai/ ujung susu kiri seperti/ yang dahulu jua adanya.

Bab ini Isim Puji/ Dina, besar faedahnya/ lagi mustajab. Maka diamal/kan tujuh hari, bermu $\{1 \mathrm{la}\}^{5}$ pada//25 (23)// hari Ahad, dibaca 500 kali siang dan/ malam tiada boleh manginang. Ini yang dibaca yâ hayyu yâ qayyūm/ Nabi Adamnabinya. Maka dito/longi malaikat lima laksa./ Dan hari senin dibaca//26 (24)// 400 kali siang/ dan malam tiada boleh makan/ ikan sewaktu itu. Ini yang/ dibaca, "Yâ Rahmân Yâ Râhîm." Nabi/ Nuh nabinya. Maka ditolongi 4 laksa. Dan/ pada hari selasa dibaca//27 (245// 300 kali siang dan/ malam tiada boleh makan apa-apa/ sewaktu itu. Inilah yang/ dibaca, "Yâ Mâlika l-Quddūs." /

\footnotetext{
${ }^{5}$ Tertulis hanya bermu, mungkin penyalinnya ketinggalan menuliskan huruf lam.
}

Nabi Ibrahim Nabinya. Maka/ ditolongi malaikat 3 laksa./Danpada hari arba' dibaa//28 (26)// 700 kali siang/ dan malam, tiada boleh mauyah (ماويه)/ sewaktu itu. Inilah yang/ dibaca, "Yâ Kabîr Yâ Mutakabbir"./ Nabi Musa nabinya. Maka dito/longi malaikat tujuh laksa./ Dan pada hari Khamis//29 (27)// dibaca 800/ kali siang dan malam tiada boleh/ minum air sewaktu itu. Inilah/ yang dibaca, "Yâ Hâlî Yâ Halîm." Nabi Idris nabinya. Maka/ ditolongi malaikat 8/ laksa. Dan pada hari jumat//30 (28)// dibaca 600 kali/ siang dan malam tiada boleh/ di makan yang masak karana sebab/ api sewaktu itu. Inilah/ yang dibaca, Yâ Kâfî Yâ Munî." Nabi Muhammad nabinya. Maka ditolongi/ malaikat 6 laksa. Dan//31 (29)// pada hari sabtu dibaca/ 900 kali siang/ dan malam, tiada boleh tidur/ sewaktu itu. Inilah yang/ dibaca,"YâFattâh Yâ Rizqî." Nabi Isa nabinya. Maka dito/longi malaikat 9 laksa//32 (30)// malaikat.

Kita di dalam beramal/ itu diminta kepada Allah Ta'âla/ barang \{yang di\} kehendaki. Kita tiada/ boleh dua talu permintaan./ Itu hanya satu aja. Tammat.

Ini Pasal Isim Jala/lah. Barang dici[n]ta ${ }^{7}$ niscaya//33 (31)//di\{a\}nugrahi Allah Ta'âla. Jika/ hendak minta kasih pada/ orang sekalian, baca isim/ ini. Jikalau kita tadapat/ malu, yaitu lampahkan/ mandi tiga isukan wayah/ manggunjur matahari/ dan//34 (32)// tilasannya kain putih, jangan/dilihat oleh dangsanak/ atau kuwitan. Kita baca

\footnotetext{
${ }^{6}$ Biasa kalau amaliyah Yâ Fattâh bergandingan dengan asma Allah Yâ Razzâq." bukan "Yâ Rizqî".

${ }^{7}$ Mungkin yang dimaksud adalah dicita
} 
tiga/ kali di dalam sekali-sekali mandi. Inilah isimnya yang dibaca, "Bismillahhirrahmânirrâhîm/ Yâ hayyun haini bi muy ikal hayyi//35 (33)//lâilâha illa l-Lâhu ila l-Haq/ hayyun mulhaq, Yâ Allâh Yâ Allâh/ ya hayyun, ya dîtu mulku uhâ/ bilika ihim, Yâ Allâh wa tarfî/ ujâlallâh.

Ini Bab/ Kata Kunci. Jikalau kita jangan/ memberikan orang baisitri,//36 (34)// atauperempuan hendak/ bersuami, atau musuh kita/ supaya ia jangan berkehendak./ Maka kita tiupkan kepadanya. Inilah/ yang dibaca, "Kunciku kunci/ alam, kunciku kunci Muhammad. Tertutup,/ terkunci mati-mati kehendak sekalian//37 (35)// yang berkendak berkat lâilâha illa l-Lâh Muhammadu r-Rasūlullâh./

Ini Doa kandung rasulu/llah. Maka sabda rasulullah/ sallahu alaihi wasallam/ kepada sayyidina Ali, “Baran siapa/ membaca doa ini dengan ikhlas//38 (36)// hati, niscaya di\{a\}nugraha/i Allah Ta'âla rizqi tiada ber/keputusan. Bermula doa/ inijika dibaca dihadapan/ raja-raja atau orang besar-orang besar,/ niscaya jadi kasih.Ber/mula doa ini tiupkan pada//39 (37)// perempuan, jadi kasih/ pada kita. Bermula jika/ kita hendak melihat/ orangdi dalam kubur, dibaca/ doa ini atas kubur/ pada hari jumat 7 kali,/ niscaya dilihat orang yang//40 (38)// di dalam kubur, membaca itu/ pada waktu subuh. Bermula/ jika hendak melihat mala/ikat, atau jin, atau syaitan, dibaca doa ini pada tempat yang/ sunyi, niscaya kelihatan/ semuanya, serta berkasih-kasihan//41 (39)// dan berkata-kata dengan kita.Bermula jika hendak pada/ orang-orang, maka usap diri/ kita dengan tinggi pada malam jumat. Baca doa ini 4 kali,/ niscaya datang pada kita.Bermula kita hendak//42 (40)// diturut orang sekalian kata./ Maka baca pada malam jumat tujuh/ belas kali, niscaya takut/ pada kita.Bermula jika kita/ masuk ke dalam hutan baca doa/ ini, niscaya sekalian binatang/ takut pada kita.Bermula//43 (41)// jika hendak menawar air / yang masin ${ }^{8}$ di laut. Maka baca/ doa ini serta rendam kaki/ kita, niscaya tawar.Bermula jika hendak dibunuh/ orang, baca doa ini tiap-tiap/ hari dan malam, niscaya tiada//44 (42)// jadi orang membunuh.Bermula jika padi kita di ma/kan tikus atau ular, baca/ doa ini 3 kali berkuliling/ pahumaan, niscaya tiada dimakan/nya lagi.Bermula jika kita/ hendak be\{r\}layar ada terdapat//45 (43)// ombak besar atau angin besar/ baca da ini, niscaya teduh./Bermula jika kita sampai/ pada negeri orang baca 9/ kali serta makrifat niscaya/ selamat. Inilah/ doanya./ / 46 (44)//

Bismillâhirrahmânirrâhîm/

Akhażtu samî'a mâ khalaqa/ l-Lâhu Ta'âla wa bașaruhum ${ }^{9} 2 x$./ Akhażtu biquwwatin mâ mâ khalaqa l-Lâhu Ta'âla wa ssultânuhum mâ mâ khalaqa l-Lâhu Ta'âla wa ș-ṣultâ/nuhu wa isyrâîlu an yamîni//47 (45)// wa isyrâfila 'an yusârî./ Allahumma mina l-Jawwâbîn hafìi/ wa hasbiya l-Lâhu wa ni ma l-wakîl/ wa ni ma l-maulâ wa ni ma l-nașîr./ Bifadlika bi quwwati rabbi/ l-'âlamin, yâ rabbi lâ haula wa/ lâ quwwata illa bi l-Lâhi l-'aliyyu//48 (46)// l-'azîm.

\footnotetext{
${ }^{8}$ asin

${ }^{9}$ Mungkin yang lebih tepat adalah bașarahum. Karenakata ini ataf kepada samí'a yang merupakan objek dari akhażtu.
} 
istajībū wa l-jinni wa l-insi an àyūna nnâzirin/ wa sy-syayâtîna wa hilâ minhum/ajma în, birahmatika yâ arhama $r$ râhimîn.

\section{Ini Bagi/ Kebesaran}

Wa asaluka bismika/ yâ fardu yâsamadu yâ abadu yâ àazzu yâ//49 (47)// ajallu yâ ahaqqu yâ abarru yâ munîru/ yâ hayyu subhânaka yâ lâilâha illa/ anta khaliṣnâ mina n-nâri./ yâ man lahu l- izzatu wa ljamâlu./ Yâ man lahu l-qudratu wa l-kamâl/ yâ man lahu l-mulku wa l-jalalu/ yâ man lahu l-kabiru l-muta'âl yâ man//50 (48)// huwa munsyiu s-sahâbi10's-siqâl yâ man huwa syadîdu/ l-mihâl yâ man indahū husnu l-fi âl yâ man huwa syadîdu/l- iqẩb, yâ man huwa indahu/ ummu l-kitâb, yâ man huwa sarî‘ $u / / 51^{11}$ (49)// l-hisâb12yâżaljalâli wa l-ikrâm/ subhânaka yâ lâilâha illa anta/ khalișnâ mina n-nâri.

\section{Ini Bagi/ melepaskan segala kejahatan/}

Wa asaluka bismika yâ gaffâru/ yâ sattâru yâ qahhâru yâ jabbâru yâl sakkâruyâsabbâru yâżakkâru yâ//52 (50)// makkâru yâ nawwâru yâ bârru. subhânaka yâ lâilâha illa anta/ khalișnâ mina n-nâri. yâ man/ tabâraka smuhu, yâ man Tåâla jadduhu, yâ man jalla syanâuhu, yâ/ man lâilaha gairuhu, yâ man taqaddasat/ asmâuhu, yâ man yadūmu baqâuhu//53 (51)// yâ mani l-'azamatu13 izâruhu, yâ mani/ l-kiriyâu ridâuhu, yâ man/lâ tu addu ni'mâuhu, yâ man lâl yuhșâ alâuhu subhânaka ya/ lâilâha illa anta hawwin alainâ/ sakarâti l-maut.

\footnotetext{
${ }^{10}$ Tertulis huwa munsyiu s-sajâbi, kelebihan titik pada huruf $z$

${ }^{11}$ Baris dalam halaman ini hanya ada 6

${ }^{12}$ Tertulis syarîu l-hisâb

${ }^{13}$ Tertulis yâ mani l- 'aẓamati seharusnya yâ mani laẓamatu
}

Ini/ melepaskan penyakit hati//54 (52)//Yâ hayyu qabla kulli hayyin ya hayya ba`da/ kulli hayyin yâ hayya l-lażi laisa kamislihîl hayyin, yâ hayya l-lażî lâ yahtâju/ ilâ kulli hayyin, yâ hayyal-lażî\{lâ\} yamūtu/ hîna yamūtu kulli hayyin, yâ hayya l-lażîyuhyi l-mauta, yâ hayya l-lażil lâ yusyârikuhū hayyun, yâ hayya l-laż̂̀ yuhyi l- izâmi a hiya ramîmun, yâ//55 (53)// [yâ] hayya l-lażî lâ yushuhu hayyun, yâ hayya l-lażi lâ ta'khużuhū sinatu/ w-walâ naumun lahū, subhânaka yâ/ lâilâha illa anta ajirnâ mina/n-nâri.//56 (54)//

Ini azimat disurat pada kertas/ dipakai jika diikatkan pada kambing ditikam tiada memberi mudarrat/ insya Allah Ta`âla.

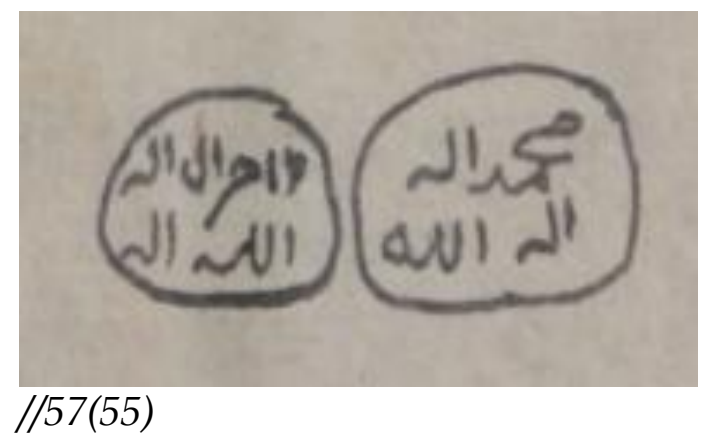

// teks pada halaman ini dicoret58 (56)// Ini namanaya banih yang laki/ Rahman dan rohnya roh mani./ Ini namanya yang/ bini Rahim, dan rohnya/ roh amani. Karena kau Nur Allah, Nur Muhammad, jangan/ engkau memakan kepada akukarena//59 (57)// ikam datang daripadaku/ inilah yang diamalkan, tujuh hari pada tiap-tiap/ bangun tidur. Ini kata giludah 'jabarun'. Ini kita kariyau yâ irâdat. Dibaruh ini kita sua//60 (58)// dâh dârūdâh, maka yaitu diamalkan / 40 hari/ tiap-tiap bangun tidur, membaca 3 kali kata ini, emoles kepada ratik.//(61 (59)//

Ini kata sapu

"aria bismi aria kifar lah aria patatai aria sanalu ah sanalu. 
Bab ini paputaran surat pada telur ayam hitam, patak pada kuburan orang besar, niscaya sakit tiada mendera. Ini rajamnya, maka surat ngaranya//62 $(60) / /$

\section{PENUTUP}

\section{Simpulan}

Naskah MM yang Berkode E. 4508 ini di simpan di Museum Lambung Mangkurat Jalan Jendral A. Yani Km. 36, Banjarmasin. Naskah ini bersampul kertas karton tebal berwarna coklat dan alas naskah kertas tebal. Ukuran naskah $10 \times 6,5 \mathrm{~cm}$, ukuran teks $7 \times 4 \mathrm{~cm}$, tebal naskah 61 halaman. Jumlah baris setiap halaman 7 baris. Kecuali pada halaman 57 yang hanya berisi 4 baris dan dua ilmunisasi. Naskah ini ditulis menggunakan bahasa Banjar berbentuk prosa beraksara Arab Melayu. Tulisan pada naskah ini menggunakan tinta berwarna hitam dan pensil sebagai penomoran. Teks ditulis dengan khat riq'î kecuali ketika memulai pasal dan Bab. Pada saat memulai pasal dan Bab, penulis biasanya menggunakan khat sulusi .

Secara tulisan, naskah ini bisa dsimpulkan ditulis oleh tiga orang. Adapun secara Isi, teks MM ini bisa dibagi tiga bagian dari tiga orang penulis naskah ini. Bagian pertama merupakan tulisan tentang sumpah kurap dan mantra tatkala bergaul dengan orang yang menderita campah agar tidak tertular campah. Bagian kedua, terdiri dari pasal dan bab, serta doa yang ditulis oleh seorang penulis.
Adapun Pasal-pasal yang terdapat dalam bagian ini berbicara dua hal, yaitu tentang cara bersahabat dengan jin, dan kesaktian.

Adapun Bab yang terdapat pada bagian ini berbicara tentang Bab Japaian, Bab Isim Puji Dina, dan Bab Kata Kunci. Bab Japaian berbicara tentang bagaimana cara memegang lidah dan puting susu sendiri dengan bacaannya. Bab Puji Dina berbicara tentang bacaan yang sangat besar manfaat dan mendapat pertolongan ribuan malaikat ketika melakukan sesuatu. Sedangkan Bab Kata Kunci mengungkapkan tentang cara agar seseorang terkunci sehingga tidak bisa beristri atau bersuami, dan tidak diserang musuh.

Pada bagian doa, terdapat beberapa macam doa, yaitu doa Kandung Rasulullah, doa agar memperoleh kewibawaan dan pangkat, doa melepaskan segala kejahatan, doa melepaskan segala penyakit hati, dan satu azimat agar kebal. Doa kandung Rasulullah itu mempunyai banyak khasiat, diantaranya mendapat rezki yang tiada putus, disayangi sama pembesar dan atasan, disayangi kekasih, dapat mengetahui dan melihat orang yang berada dalam kubur, untuk melihat malaikat dan setan, mempunyai pengaruh dan selalu dipatuhi, ditakuti binatang, membuat air laut menjadi tawar, agar orang tidak jadi berbuat jahat, agar sawah dan ladang tidak dimakan tikus, meredakan ombak dan angin besar, agar selamat di negeri orang. 


\section{DAFTAR PUSTAKA}

Baried, Siti Baroroh, dkk., 1994. Pengantar Teori Filologi. Yogyakarta: Fakultas Sastra UNS.

Behrend, T.E. (ed.). 1994. Katalog Induk Naskah-naskah Nusantara Jilid 4: Perpustakaan Nasional Republik Indonesia. Jakarta: Yayasan Obor Indonesia dan EFEO.S.

Diyab, abdul majid. 1993.Tahqiq al-turast alArabi, manhajuhu wa tatawuruhu. Kairo: Dar al-ma'arif.

Djamaris, Edwar. 2009. Filologi Dan Cara Kerja Penelitian Filologi. Makalah. 20 April 2009

Harun, Abdussalam. 1998.Tahqiqun an-nusus wa nasyruha. Kairo: Maktabah al-khaniji bil qahirah.

Hidayatullah. Dede. 2009. Jenis dan fungsi mantra dalam masyarakat Banjar. Bunga Rampai Sastra Hasil Penelitian. Banjar Baru: Balai Bahasa provinsi Kalimantan Selatan.

--------. 2014. Revitalisasi Mantra Banjar. Makalah. disampakan pada seminar Nasional Bahasa Daerah (Sembada) tanggal 10 - 11 Sepetember 2014 di Martapura.

--------. 2014. Naskah Ini Fasal Pada Menyatakan Jalan Yang Benar karya Nuruddin Ar-Raniry dalam Naskah Negara: Edisi Suntingan Teks. Prosiding.Disampaikan pada Diskusi Ilmiah (Lokakarya Hasil Penelitian) Kebahasaan dan Kesasteraan. di Yogyakarta 29 September-1Oktober 2014.

-------. 2015. Naskah Martabat Tujuh: Edisi Kodikologi Dan Isi Naskah. Jurnal Undas. Banjarbaru: Balai Bahasa Kalimantan Selatan.

Humaidy, dkk. 2011. Studi Naskah Syarâb al-'Âsyiqîn Karya Hamzah Fansuri dalam Naskah Negara. Banjarmasin: Puslit IAIN Antasari.

Mu'jizah. 2005. Martabat Tujuh: Edisi Teks dan Pemaknaan Tanda serta Simbol. Jakarta: Djambatan.

Munadi, dkk. 2011. Konsep Shalat Menurut Ihsanuddin Sumatrani Dalam Asrâr Al-Salât. Banjarmasin: Puslit IAIN Antasari.

Rohim, Khairur dan Rustam Effendi.2014 Nilai Budaya Dalam Mantra Banjar. Jurnal bahasa dan sastra 204-214.

Sunarti, dkk. 1978. Sastra Lisan Banjar. Jakarta: Pusat Pembinaan dan Pengembangan Bahasa.

Tim Penyusun. 2005. Mantra Banjar. Banjarbaru: Balai Bahasa Banjarmasin.

Tjandrasasmita, Uka. 2006. Kajian Naskah-naskah Klasik dan Penerapannya bagi Kajian Sejarah Islam di Indonesia. Jakarta: Pusdiklat Lektur Keagamaan Departemen Agama RI.

Yudiafi, Siti Zahra dam Mu`zijah. 2010. Filologi. Jakarta: Penerbit Universitas Terbuka. 
Undas Vol 12., Nomor 2, Desember 2016 : 117--133

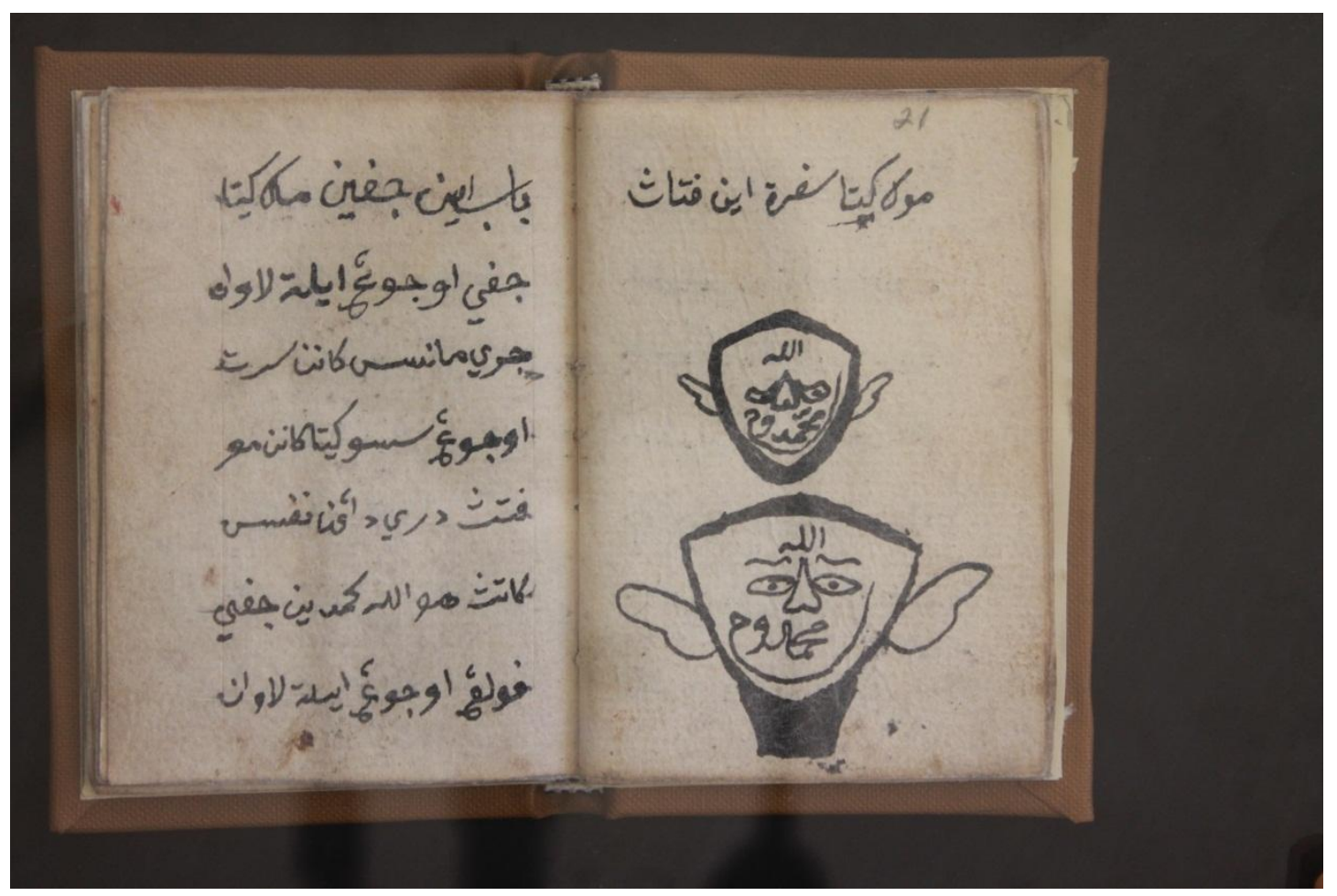

